\title{
Fe-Al-Si coatings for the Protection of Steel Against High-temperature Oxidation
}

\author{
Pavel Novák, Abir Lamchaouri, Kateřina Nová, Filip Průša \\ University of Chemistry and Technology, Prague, Department of Metals and Corrosion Engineering, Technická 5, 166 \\ 28 Prague 6, Czech Republic, E-mail: panovak@vscht.cz
}

\begin{abstract}
Fe-Al-Si alloys based on Fe-Al, Fe-Si and ternary Fe-Al-Si phases have been recently proved as the materials highly resistant to high-temperature oxidation. However, high brittleness limits their application as bulk materials. Therefore this work aims to test them as the protective coatings for the carbon steel and to test the high-temperature oxidation resistance of the coated samples. The coatings by FeAl32, FeAl35Si5 and FeAl20Si20 alloys were produced uncoventionally by the combination of mechanical alloying and spark plasma sintering. It has been shown that the best resistance against the oxidation in the air at $800^{\circ} \mathrm{C}$ was reached in the case of the $\mathrm{FeAl} 35 \mathrm{Si} 5 \mathrm{coating}$. FeAl binary alloy coating oxidized more rapidly, while the FeAl20Si20 coating tended to delaminate.
\end{abstract}

Keywords: Fe-Al-Si coatings, spark plasma sintering, high-temperature oxidation

\section{Introduction}

The history of iron intermetallics reaches back to 1890 's, when the positive effect of aluminium was reported by Borsig [1]. The high-aluminium steels were brittle and so the research on iron aluminide materials continued a bit longer in 1950's [2]. In that period, the Fe-Al-C alloys were developed, being processed by casting. However, the alloys contained $\mathrm{Al}_{4} \mathrm{C}_{3}$ aluminim carbide, which decomposes to methane under certain conditions. Hence the current research is focused mostly on the low-carbon or carbon-free aluminide-based materials. Many alloying elements have been tested recently, such as chromium, niobium or zirconium $[3,4]$. Our team developed $\mathrm{Fe}-\mathrm{Al}$ Si alloys, which showed excellent oxidation resistance in air and thermal stability of mechanical properties at the temperatures up to $1000{ }^{\circ} \mathrm{C}$ [5]. However, the alloys are inherently brittle due to the presence of hard but brittle silicides. The use of mechanical alloying enabled to obtain ultrafine material with improved fracture toughness, but the value $\left(3.50 \pm 0.33 \mathrm{MPa}^{1 / 2}\right)[6,7]$ is still too low for many applications. Therefore, this work aims at testing the applicability of these ultrafine Fe-Al-Si materials as coatings. In order to keep the advatages of ultrafine structure, we used mechanical alloying for the powder production. The prepared powder was trasformed to a coating by the means of spark plasma sintering method, which is a modern process for sintering of materials [8]. The application of this method for coatings and layered systems is very unusual and innovative [9].

\section{Experimental}

The alloys coatings of the chemical composition FeAl32, FeAl35Si5 and FeAl20Si20 (in wt. \%) were prepared on the substrate of a carbon steel (EN 1.1141) by non-conventional powder metallurgy process. It comprised the ultr-high energy mechanical alloying procedure developed by authors and spark plasma sintering. Ultrahigh energy mechanical alloying uses the highest energy possible, employing also high friction force and corresponding temperature increase to synthesize intermetallics by thermally activated reactions [10]. Therefore, lubrication was not used during this process. It was carried out in planetary ball mill Retsch PM 100 CM under following conditions - a milling duration of $10 \mathrm{~h}$, change of rotation direction each $30 \mathrm{~min}$, a rotation speed of $400 \mathrm{rpm}$, powder batch per one milling process $20 \mathrm{~g}$, ball-to-powder weight ratio of 15:1. Material of the milling jar and balls made of stainless steel and the milling jar was filled by argon during the process. For mechanical alloying, following elemental powders were applied: iron (purity $99.9 \%$, particle size $<44 \mu \mathrm{m}$ ), aluminum (purity 99.7\%, particle size $<44 \mu \mathrm{m}$ ) and silicon (purity $99.5 \%$, particle size $<44 \mu \mathrm{m}$ ). The alloy powders produced by mechanical alloying were applied on all surfaces of the carbon steel disc in the graphite die and sintered by spark plasma sintering using a FCT HP D10 device. Conditions for sintering were following: pressure of $48 \mathrm{MPa}$, temprature of $1000^{\circ} \mathrm{C}$, duration of $10 \mathrm{~min}$, heating rate $300{ }^{\circ} \mathrm{C} / \mathrm{min}$, cooling rate $50{ }^{\circ} \mathrm{C} / \mathrm{min}$, batch for sintering was $5 \mathrm{~g}$.

Microstructure of the alloy coatings was studied on the cross-cuts by the means of TESCAN VEGA 3 scanning electron microscope in the backscattered electrons mode (SEM-BSE). Phase composition was determined by X-ray diffraction analysis (XRD) using a PANalytical X'Pert Pro X-ray diffractometer.

Cyclic oxidation tests were carried out at $800{ }^{\circ} \mathrm{C}$ in air. The oxidation rate was determined from weight gains caused by oxidic formation on the surface of thermally exposed samples. The duration of one oxidation cycle was $50 \mathrm{~h}$ and the total cycle was $300 \mathrm{~h}$. After each cycle, samples were air-cooled, weighed by analytical balance $(\mathrm{d}=0.0001 \mathrm{~g})$, and heated again to the test temperature. Oxidation is usually controlled by the diffusion of oxygen or oxidized element through the oxidic layer, and therefore the results were fitted by the parabolic law, presented by Equation (1):

$$
\left(\frac{\Delta \mathrm{m}}{\mathrm{A}}\right)^{2}=\mathrm{kp} \cdot \mathrm{t}
$$

where $\mathrm{kp}, \Delta \mathrm{m}, \mathrm{A}$, and $\mathrm{t}$ are parabolic rate constant $\left(\mathrm{g}^{2} \mathrm{~m}^{-4} \mathrm{~s}^{-1}\right)$, weight gain $(\mathrm{g})$, exposed area $\left(\mathrm{m}^{2}\right)$ and duration of oxidation (s), respectively [7].

Microstructure of the oxidic layers and their chemical composition were evaluated on the cross-cuts by the means of SEM-BSE and energy dispesive spectroscopy (EDS) using Oxford Instruments X-max $20 \mathrm{~mm}^{2}$ detector 
and Aztec software package. Phase composition of the oxidic layers was identified by XRD.

\section{Results and Discussion}

Microstructure of the prepared coatings is shown in Fig.1. It can be seen that the FeAl layer is more porous than the Fe-Al-Si ternary ones due to worse sinterability of the FeAl phase. All of the alloy coatings contain sporadic cracks, probably due to a difference in thermal expansion of the coating and the steel substrate. In all layers,
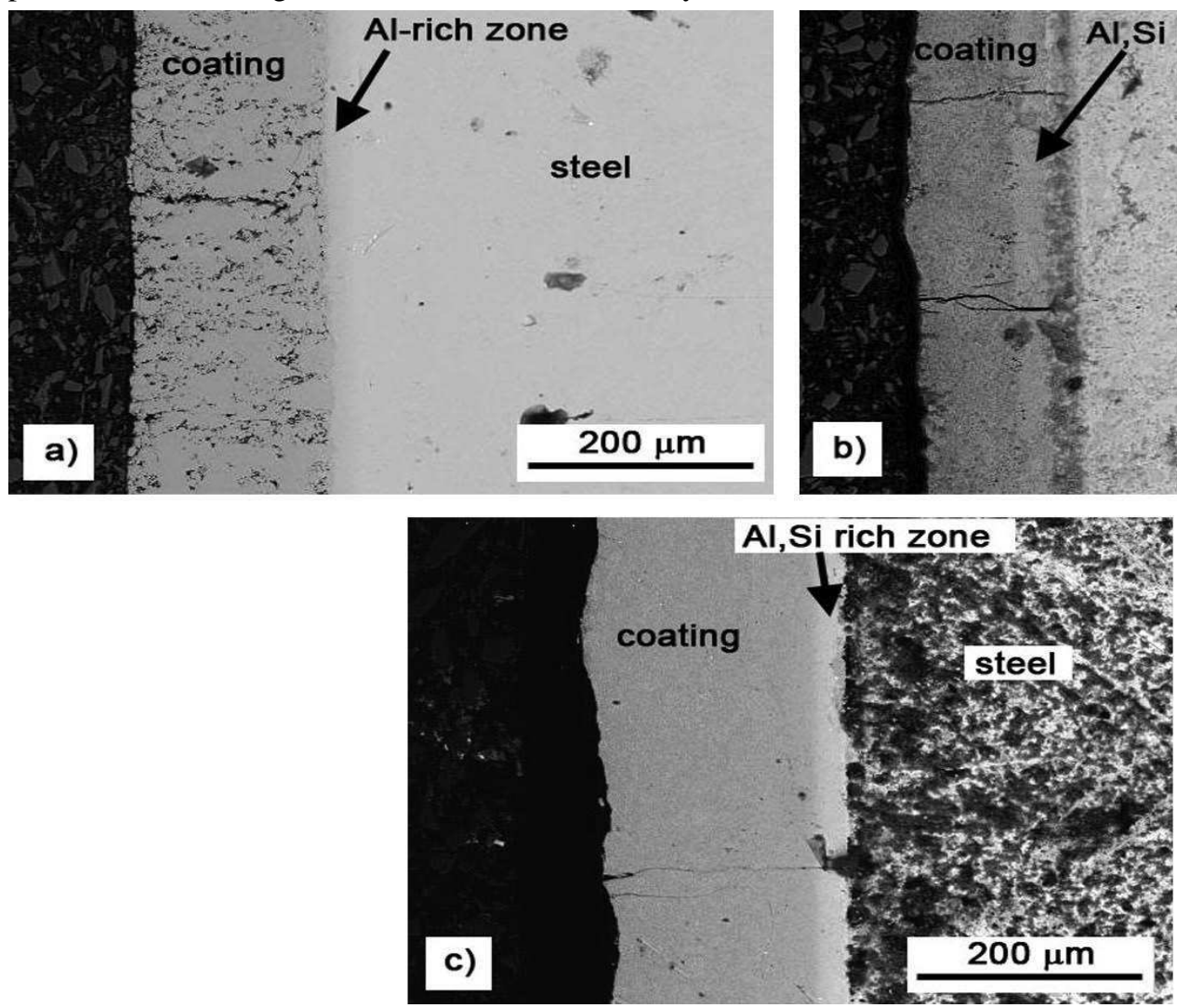

Fig. 1 Microstructure (SEM-BSE) of the coatings: a) FeAl32, b) FeAl35Si5, c) FeAl2OSi2O

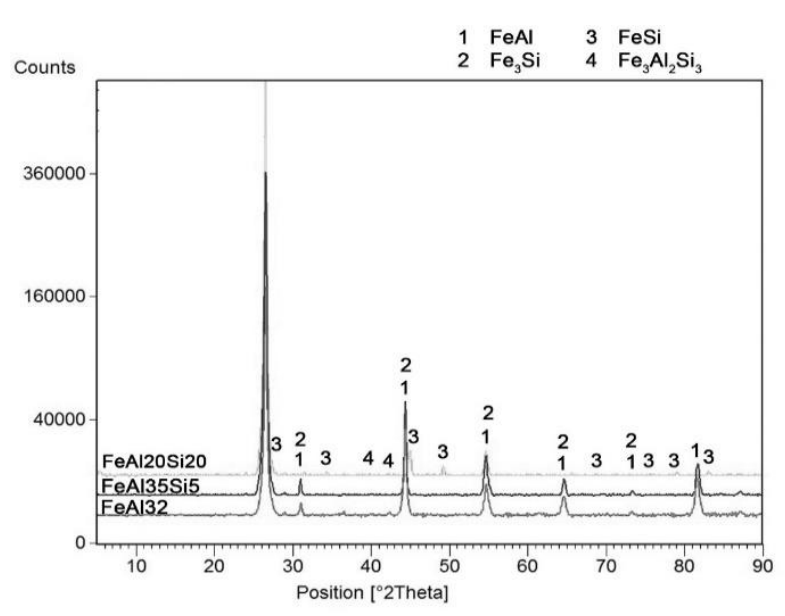

Fig. 2 XRD patterns of the coatings.

The phase composition of the coatings is shown in the form of XRD patterns in Fig.2. The FeAl32 and FeAl35Si5 coatings are composed of $\mathrm{B} 2 \mathrm{FeAl}$ ordered phase only according to XRD. However, it is highly expected that the $\mathrm{FeAl} 35 \mathrm{Si} 5$ alloy contains also $\mathrm{Fe}_{3} \mathrm{Si}$, but

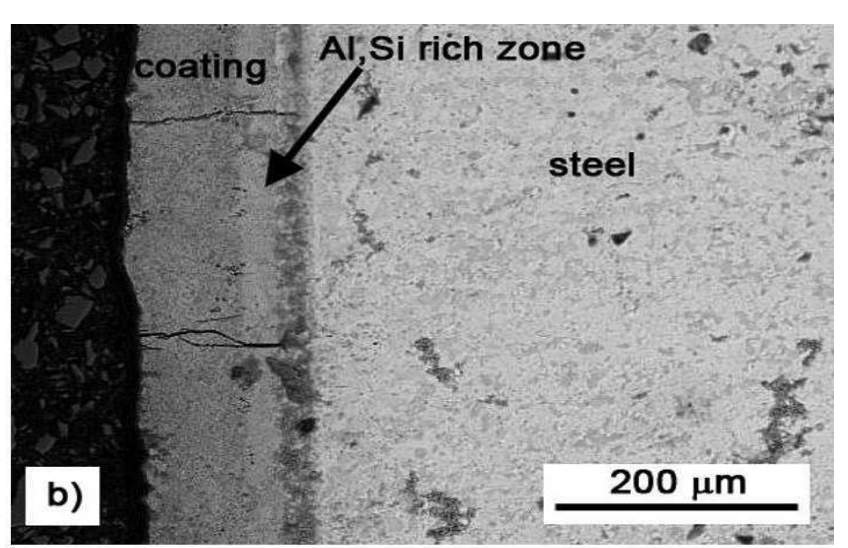

there is also an inner sub-layer, which was identified by EDS as the aluminium-rich ferrite phase (disordered bcc structure), containing 6 - 7 wt. $\%$ of aluminium and up to 7 wt. $\%$ of silicon, depending on the alloy composition. This layer, originating from mutual diffusion of iron from the steel and aluminium and silicon from the layer, can act as the secondary oxidation protection, because aluminium is frequently added to the heat resistant steels in order to improve the oxidation resistance. 
constants are following: $2.1 \times 10^{-6} \mathrm{~g}^{2} \mathrm{~m}^{-4} \mathrm{~s}^{-1}$ for FeAl32, $3.8 \times 10^{-7} \mathrm{~g}^{2} \mathrm{~m}^{-4} \mathrm{~s}^{-1}$ for FeAl35Si5 and $1.7 \times 10^{-6} \mathrm{~g}^{2} \mathrm{~m}^{-4} \mathrm{~s}^{-1}$ for FeAl20Si20 coating. It confirms really slow oxidation of FeAl35Si5 coating, while the FeAl32 layer and FeAl20Si20 oxidized by rate of the same order, even though the FeAl32 coating was quite porous and the FeAl20Si20 one was more homogeneous with sporadic cracks only (Fig. 1).

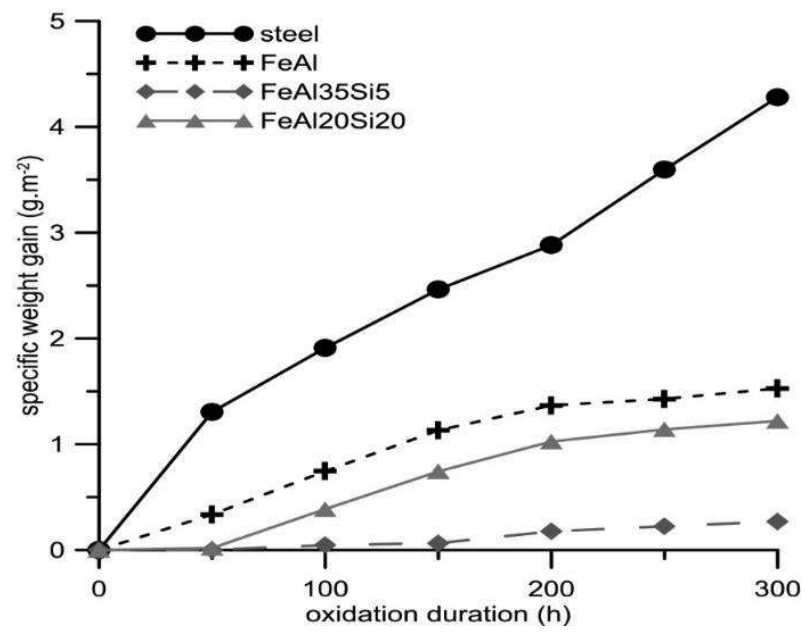

Fig.3. Specific weight gain caused by oxidation at 800 ${ }^{\circ} \mathrm{C}$ vs. oxidation duration

XRD analysis of the oxide layers revealed aluminium oxide (cubic $\alpha-\mathrm{Al}_{2} \mathrm{O}_{3}$ ) as the main oxidation product of the coated samples (Fig. 4). The other oxidation products of the coated samples are $\mathrm{FeO}$ and $\mathrm{Fe}_{2} \mathrm{O}_{3}$, depending on the alloy composition. Iron oxides are known to lower the protective effect of the oxidic layers [11]. From the intensity of the diffraction lines it could be assumed that the lowest amount of iron oxides is in the oxidic layer on the FeAl35Si5 coating. It was proved by the chemical analysis by the EDS method (Tab. 1).

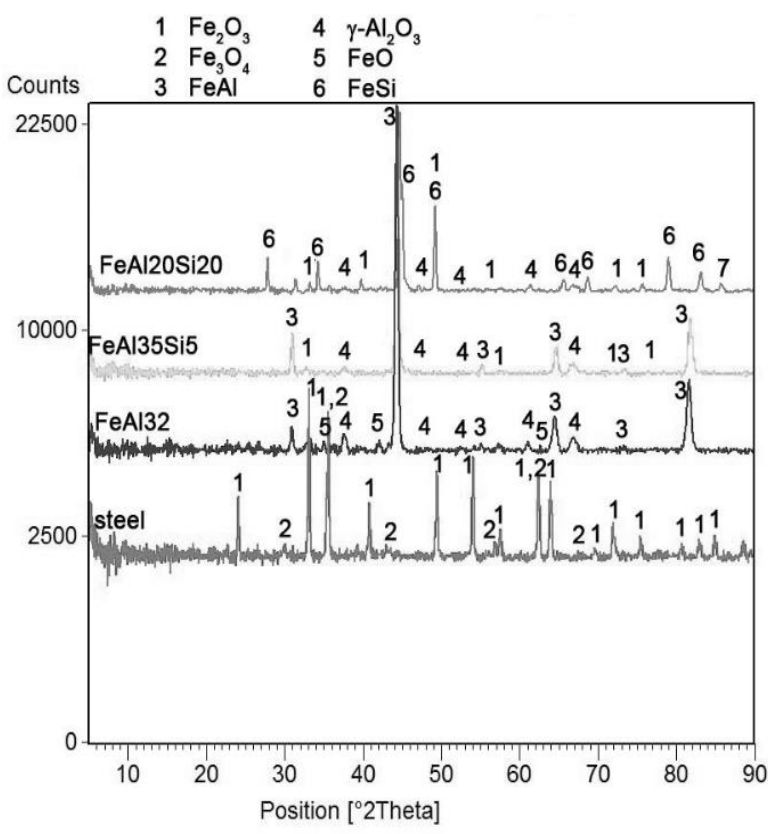

Fig. 4 XRD patterns of the coatings after oxidation at $800^{\circ} \mathrm{C}$.

Tab.1. Chemical composition of the oxidic layers.

\begin{tabular}{|l|c|c|c|c|}
\hline Coating & Al & Fe & Si & O \\
\hline FeAl & $37.7 \pm 1.7$ & $33.2 \pm 2.6$ & & $29.0 \pm 1.0$ \\
\hline FeAl35Si5 & $51.6 \pm 3.1$ & $7.4 \pm 1.3$ & $1.4 \pm 0.7$ & $39.5 \pm 4.2$ \\
\hline FeAl20Si20 & $46.7 \pm 3.1$ & $10.9 \pm 3.4$ & $7.3 \pm 0.4$ & $36.8 \pm 3.2$ \\
\hline uncoated steel & & $75.5 \pm 5.8$ & & $24.5 \pm 5.8$ \\
\hline
\end{tabular}

The differences in the oxidation behaviour can be explained clearly on the basis of the observation of the microstructure of the coated samples in a cross-cut (Fig.5). The oxidic layer on the uncoated steel is porous and not adherent (Fig. 5d) and hence it cannot provide any surface protection. Therefore the oxidation is controlled

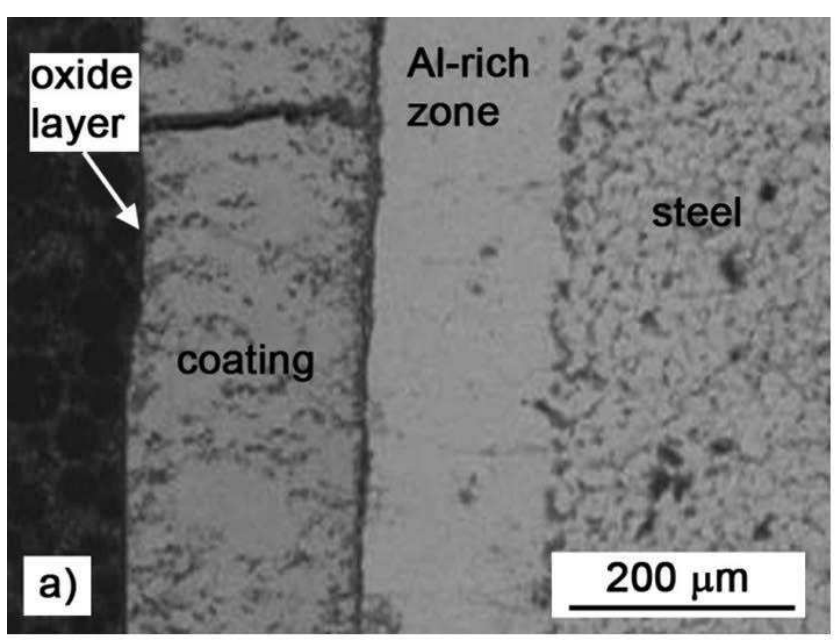

just by the rate of the chemical reaction without the limitation by diffusion of reactants. On the other hand, there are only very thin oxidic layers on the coated samples (Fig.5a-c). In addition to the continuous thin aluminiumrich oxidic layer, there are also various forms of internal oxidation visible in coated samples.

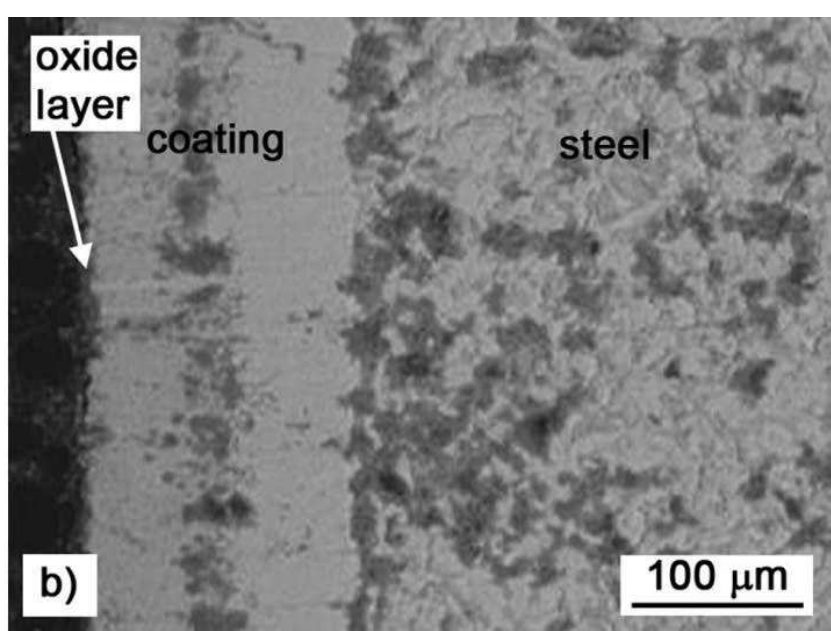



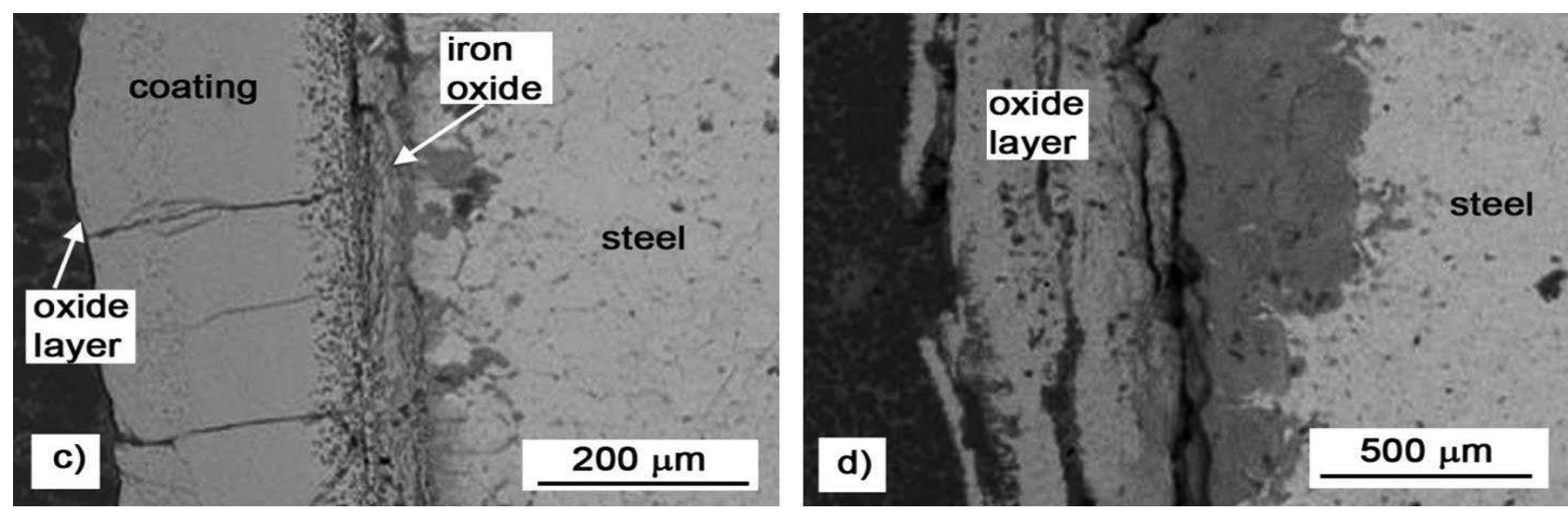

Fig.5. Microstructure (SEM-BSE) of the samples after 300 h oxidation at $800^{\circ} \mathrm{C}:$ a) FeAl32 coating, b) FeAl35Si5 coating, c) FeAl20Si20 coating, d) uncoated steel.

In the case of FeAl32 coating, the particles of oxide are located mostly in the coating in the vicinity of the pores and cracks (Fig. 5a). Similar situation is in the case of the FeAl35Si5 layer but with limited areas of oxides (Fig. $5 b)$. On the contrary, the FeAl20Si20 coating does not contain almost any oxidized areas inside, but there is a nearly continuous oxidic layer (iron oxide) below the oxidic layer (Fig.5c). This layer results in the spallation of the coating. The reason for the internal oxidic layer below the coating lies in numerous cracks in the oxidic layer, being probably caused by low thermal expansion coefficient of the coating based mostly on silicides in comparison with the steel.

\section{Conclusions}

This paper proved that the Fe-Al-Si layers could be beneficial for the improvement of the high-temperature oxidation resistance of a steel, especially the coating with higher aluminium-to-silicon ratio. The suitable coating (FeAl35Si5) can lower the oxidation rate of carbon steel more than 10 times. The oxidation behaviour was tested on the samples coated by the innovative method, which is good for laboratory tests and in the case of practical application only for smaller flat products. For the industrial application, the other available techniques, such as thermal spraying or plasma surfacing, have to be used.

\section{Acknowledgement}

This research was financially supported by the Czech Science Foundation, project No. 17-07559S.

\section{References}

[1] BORSIG, A. (1894). Zusatz von Aluminium zum Roheisen, In: Stahl und Eisen, Vol. 14, pp. 6.

[2] KRATOCHVÍL, P. (2008). The history of the search and use of heat resistant Pyroferal alloys based on FeAl. In: Intermetallics, Vol. 16, pp. 587-591.

[3] VODIČKOVÁ, V., HANUS, P. (2015). The Effect of Zirconium and Carbon Addition on Thermal Expansion of $\mathrm{Fe}_{3} \mathrm{Al}$-Based Iron Aluminides.
In: Manufacturing Technology, Vol. 15, pp. 739743

[4] HOTǍ̌. A., HOTǍ̌, V. (2015). Fractal Geometry Used for Evaluation of Corrosion Resistance of Fe-14Al-6Cr Wt. \% against Molten Glass, In: Manufacturing Technology, Vol. 15, pp. 534-541.

[5] NOVÁK, P.; NOVÁ, K.; PRŮŠA, F.; VANKA, T. (2018). High-temperature behaviour of new FeAl-Si alloy produced by powder metallurgy. In: Manufacturing Technology, Vol. 18, pp. 299-302.

[6] NOVÁ, K.; NOVÁK, P.; PRŮŠA, F.; VANKA, T. (2018). The effect of production process on properties of FeAl20Si20. In: Manufacturing Technology, Vol. 18, pp. 295-298.

[7] NOVÁK, P., VANKA, T., NOVÁ, K., STOULIL, J., PRŮŠA, F., KOPEČEK, J., HAUŠILD, P., LAUFEK, F. (2019). Structure and Properties of Fe-Al-Si Alloy Prepared by Mechanical Alloying. In: Materials Vol. 12, 2463.

[8] MICHALCOVÁ, A., PALM, M., SENČEKOVÁ, L., ROLINK, G., WEISHEIT, A., KUBATÍK, T.F. (2015). Microstructures of Iron Aluminides Processed by Additive Layer Manufacturing and Spark Plasma Sintering. In: Manufacturing Technology, Vol. 15, pp. 610-614.

[9] CHANDRA, T., IONESCU, M., MANTOVANI, D. (2012). Shaping of Nanostructured Materials or Coatings through Spark Plasma Sintering. In: $M a-$ terials Science Forum, Vol. 706-709, pp. 24-30.

[10] NOVÁ, K.; NOVÁK, P.; PRŮŠA, F.; KOPEČEK, J.; ČECH, J. (2019). Synthesis of Intermetallics in Fe-Al-Si System by Mechanical Alloying. In: $M e-$ tals, Vo. 9, 20.

[11] NOVÁK, P., NOVÁ, K. (2019). Oxidation Behavior of $\mathrm{Fe}-\mathrm{Al}, \mathrm{Fe}-\mathrm{Si}$ and $\mathrm{Fe}-\mathrm{Al}-\mathrm{Si}$ Intermetallics. In: Materials, Vol. 12, 1748. 